\title{
Melatonin, calcium and vitamin D levels in adolescent idiopathic scoliosis
}

\author{
Alexandru HERDEA ${ }^{1,2}$, Adham CHARKAOUI3,4, Alexandru ULICl ${ }^{1,2}$ \\ ${ }^{1}$ Paediatric Orthopaedics, "Grigore Alexandrescu" \\ Children's Emergency Hospital, Bucharest, Romania \\ 2"Carol Davila" University of Medicine and Pharmacy, Bucharest, Romania \\ ${ }^{3}$ Paediatric Surgery, Municipal Emergency Hospital, Moinesti, Romania \\ ${ }^{4}$ Faculty of Medicine and Pharmacy, "Dunarea de Jos" University, Galati, Romania
}

\begin{abstract}
Introduction. Several causes have been proposed to underlie the onset and development of adolescent idiopathic scoliosis, but limited data have been published to date on the relationship between 25-OH-vitamin $D$, calcium, melatonin and adolescent idiopathic scoliosis.

Objective. The present study evaluates the serum level of 25-OH-vitamin $\mathrm{D}$, calcium and melatonin in relation to the age and sex of the patient, the Cobb angle, the seasonal variation of vitamin $D$.

Materials and methods. A retrospective study was conducted during 2017-2019 in which patients suffering from adolescent idiopathic scoliosis, with a Cobb angle above 10 degrees, were analyzed. Statistical significance was determined using a $P$ value of less than 0.05 in a $95 \%$ confidence interval.

Outcomes. A total of 101 patients were included in the study, with a mean age of $11.61+/-2.33,76 \mathrm{fe}-$ males and 25 males. The Cobb angle was on average $26.210+/-12.37$. Serum levels of vitamin $D$, calcium and melatonin were $24 \mathrm{ng} / \mathrm{ml}+/-9.64,9.82 \mathrm{mg} / \mathrm{dl}+/-0.42,8.82 \mathrm{pg} / \mathrm{ml}+/-6.75 .55 .44 \%$ had a sub-normal level of melatonin, $40.59 \%$ had insufficient levels of vitamin D. Calcium levels were within normal parameters. Melatonin level was positively correlated with vitamin D level ( $p=.017654, r=0.2357)$. Vitamin D level correlated positively with calcium level ( $p=0.01, r=0.973)$, but also with the patient's age $(p<0.001$, $r=0.158)$. Cobb angle was negatively correlated with serum vitamin D level $(p<0.01, r=-0.472)$. Using a 30 degree Cobb angle as a cut off point, it was observed that vitamin $D$ levels did not differ significantly $(p=0.06)$, but a positive correlation was observed between melatonin level and the two groups $(p<0.00001)$.

Conclusions. In the studied population, the calcium level remained constant within normal limits, but vitamin D and melatonin had a low level. Males had lower levels of vitamin D. As the Cobb angle increased, the serum levels of vitamin $D$ and calcium decreased. Patients with idiopathic scoliosis should be followed from the beginning for these tests and their changes. Vitamin $D$ and melatonin may be more important factors than have been considered so far in the onset and aggravation of idiopathic scoliosis. Larger studies, in larger populations, should be done to see if the administration of melatonin, vitamin $D$ and calcium can have an effect on the evolution of idiopathic scoliosis of the adolescent.
\end{abstract}

Keywords: melatonin, vitamin D, 25-OH-vitamin D, calcium, scoliosis, adolescent idiopathic scoliosis 


\section{INTRODUCTION}

Adolescent idiopathic scoliosis represents the three-dimensional structural deformity of the spine, which usually develops after the age of 9 years $[1,2]$. Scoliosis affects between 2 and $4 \%$ of adolescents and about $10 \%$ of them will need a treatment method [2].

Although it is titled as idiopathic in nature, two factors remain unanimously accepted: the genetic factor and the hormonal factor $[3,4]$.

Positive family history, respectively the genetic factor, give a $38 \%$ chance of inheriting scoliosis, while $62 \%$ are attributed to independent factors [5]. Among the independent factors are hormonal factors, studied intensively in the specialty literature, such as calmodulin [6], growth hormone [7], estrogen hormone [8], melatonin [9-11].

In patients with idiopathic scoliosis, osteopenia and low bone density are often encountered, which can influence the evolution and prognosis of the disease. [12-14]. For a good bone density an optimal level of vitamin $D$ and calcium is needed, elements that contribute to lower the incidence of fractures but also to improving the neuromuscular function $[15,16]$.

Since the last century, scoliosis has been studied in laboratory animals to try to establish the etiology of this disease $[17,18]$. Studies conducted by Machida M et al. on pinealectomized chicken have long been a subject of controversy [19]. Following the ablation of the pineal gland, the melatonin level decreases, leading to the appearance of scoliosis to the chicken $[20,21]$.

\section{OBJECTIVES}

Given the important role that vitamin D, calcium and melatonin can play in the etiology and development of idiopathic scoliosis of the adolescent, the present study proposes to verify the association between $25-\mathrm{OH}$-vitamin $\mathrm{D}$, calcium, melatonin and the following variables: gender, age, Cobb angle. The seasonal variation for vitamin $D$ will also be taken into account.

\section{MATERIALS AND METHODS}

\section{Study design and population}

The study was done in an urban area children's emergency hospital in the Pediatric Orthopedic outpatient clinic between June 2017 and October 2019.

We chose to conduct a prospective study, unblinded, non-interventional for patients diagnosed with adolescent idiopathic scoliosis, with a Cobb angle greater than $10^{\circ}$. The following were exclusion criterias: scoliosis other than idiopathic in nature (lower limb ine- quality, congenital malformations, hemivertebras, muscle distrophy), postural scoliosis, known metabolic or endocrine diseases, patients wich previously had a fracture history.

A local ethical committee approved this study. A written informed consent was obtained from the parents of all the participants.

All procedures were in accordance with the ethical standards of the institutional research committee (Centre of Postgraduate Medical Education) and with the 1964 Helsinki declaration and its later amendments or comparable ethical standards. This study was approved by the Ethical Committee of "Grigore Alexandrescu" Children's Emergency Hospital. Informed consent, as stated above, was obtained from all individual participants included in the study.

\section{Study protocol}

Patients who met the above criterias were invited to do the following blood analysis: $25-\mathrm{OH}$-vitamin D, Total calcium level and melatonin. 25-OH-vitamin $\mathrm{D}$ was considered normal with values between $30 \mathrm{ng} / \mathrm{ml}$ and $100 \mathrm{ng} / \mathrm{ml}$, deficient between $20 \mathrm{ng} / \mathrm{ml}$ and 29ng/ $\mathrm{ml}$, insuficient with values below $20 \mathrm{ng} / \mathrm{ml}$. Total calcium was considered normal with values between 8.80 $\mathrm{mg} / \mathrm{dl}$ and $10.6 \mathrm{mg} / \mathrm{dl}$. Melatonin level was considered normal between 8 and $16 \mathrm{pg} / \mathrm{ml}$ if it was assessed at 8:00 a.m. and 3-8 pg/ml if it was assessed at 9:00 a.m. In order to have the smallest variations in the study group, all participants were invited to do blood tests in the morning at 8 o'clock, in the same laboratory, under the same conditions. Patients were excluded if they had positive history for recent intake of vitamin $D$, calcium or melatonin supplements.

\section{Collection of data and statistical analysis}

Demographic data, vitamin D, calcium, melatonin, Cobb angle were analyzed statistically. Sex was analyzed using the $\chi 2$ test. Seasonal effects of vitamin D serum level were calculated using one-way ANOVA. Pearson's product-moment correlation was used to see the correlation between vitamin D level, melatonin and age, Cobb angle. Statistical significance was determined using a P value of less than 0.05 in a 95\% confidence interval. Analyses were performed with the Statistical Package for the Social Sciences (SPSS) 18.0 software.

Vitamin D (25-OH vitamin D3) was analyzed using Architect i2000 (II), CMIA (chemiluminescent microparticle immunoassay) method. Total calcium was analyzed on Beckman Coulter AU680 by spectrophotometric method. Melatonin (MELA) was analyzed by LCMS method. 
TABLE 1. Distribution of patients by age, level of melatonin, vitamin D and calcium, Cobb angle in the patient group

\begin{tabular}{|l|c|c|c|c|c|}
\hline & Age & Melatonin & 25-OH-vitamin D & Calcium & Cobb angle \\
\hline Total & 101 & 101 & 101 & 101 & 101 \\
\hline Average & 11,61 & 8,82 & 24 & 9,82 & 26,21 \\
\hline SD & 2,33 & 6,75 & 9,64 & 0,42 & 12,37 \\
\hline Median & 12 & 6,8 & 22 & 9,8 & 28 \\
\hline Min & 8 & 1 & 9,3 & 9 & 11 \\
\hline Max & 16 & 24 & 42 & 10,5 & 60 \\
\hline $95 \% \mathrm{Cl}$ & {$[11.15,12.06]$} & {$[7.5,10.1]$} & {$[22.12,25.88]$} & {$[9.73,9.90]$} & {$[23.79,28.62]$} \\
\hline
\end{tabular}

\section{OUTCOMES}

In our study, 101 patients met the selection criteria, aged between 8 and 16 years, 76 females and 25 males, evaluated and followed within our institution, between June 2017 and October 2019, diagnosed with idiopathic scoliosis. The average age of the patients was $11.61+/-2.33$, with $95 \% \mathrm{Cl}$ between 11.15 and 12.06 , as shown in table 1.

Melatonin level was on average $8.82 \mathrm{pg} / \mathrm{ml}+/$ 6.75 , with a $95 \% \mathrm{Cl}$ between $[7.5,10.1]$. The level of vitamin $D$ in the group of patients was on average 24 $\mathrm{ng} / \mathrm{ml}+/-9.64$, with a $95 \% \mathrm{Cl}$ between $[22.12,25.88]$. Calcium values were within the normal range, all patients were within a normal range, with an average of $9.82 \mathrm{mg} / \mathrm{dl}+/-0.42$. The average Cobb angle in the patient group was $26.21^{\circ}+/-12.37^{\circ}$, with a $95 \% \mathrm{Cl}$ between $[23.79,28.62]$, the maximum being 60 degrees and the minimum 11 degrees.

TABLE 2. Overall visualization of the serum level of melatonin in the patient group

\begin{tabular}{|l|c|c|}
\hline Serum level & Melatonin (pg/ml) & Number (\%) of patients \\
\hline High & $>16$ & $16(15.84 \%)$ \\
\hline normal & $8-16$ & $29(28.71 \%)$ \\
\hline insufficient & $<8$ & $56(55.44 \%)$ \\
\hline
\end{tabular}

The distribution of the serum level of melatonin divided by categories for the group of patients is shown in table 2. More than half of the patients $(55.44 \%)$ showed sub-normal values of melatonin. Only 29 patients $(28.71 \%)$ had a normal level of melatonin.

TABLE 3. Overall view of the level of vitamin $D$ in the group of patients

\begin{tabular}{|l|c|c|}
\hline Serum level & $\begin{array}{c}\text { 25-OH-vitamin D } \\
\text { (ng/ml) }\end{array}$ & Number (\%) of patients \\
\hline normal & $>30$ & $28(27.72 \%)$ \\
\hline defficient & $20-29$ & $32(31.68 \%)$ \\
\hline insufficient & $<20$ & $41(40.59 \%)$ \\
\hline
\end{tabular}

The distribution of the 25-OH-vitamin D level divided by categories for the patient group is shown in table 3. Almost 3 quarters of the patients $(72.27 \%)$ showed sub-normal values of vitamin D. A good part of the study group $(40.59 \%)$ entered the category of patients with insufficient serum level. $31.68 \%$ had an defficient level.

TABEL 4A. Comparison between vitamin D level and gender of the patient

\begin{tabular}{|l|c|c|}
\hline 25-OH-vitamin D & Female & Male \\
\hline Total & 76 & 25 \\
\hline Average & 25.45 & 19.6 \\
\hline SD & 10.26 & 5.43 \\
\hline Median & 22 & 19 \\
\hline Min & 9.3 & 13 \\
\hline Max & 42 & 30 \\
\hline$P^{*}$ & \multicolumn{2}{|c|}{0,02} \\
\hline $95 \% \mathrm{Cl}$ & {$[23.14,27.75]$} & {$[17.47,21.72]$} \\
\hline
\end{tabular}

*Chi-Square test

TABEL 4B. Comparison between melatonin level and gender of the patient

\begin{tabular}{|l|c|c|}
\hline Melatonin & Female & Male \\
\hline Total & 76 & 25 \\
\hline Average & 8.34 & 10.28 \\
\hline SD & 5.44 & 9.55 \\
\hline Median & 7 & 6 \\
\hline Min & 1 & 1.9 \\
\hline Max & 22 & 24 \\
\hline$P^{*}$ & \multicolumn{2}{|c|}{.145} \\
\hline $95 \% \mathrm{Cl}$ & {$[6.88,9.12]$} & {$[6.47,13.5]$} \\
\hline
\end{tabular}

*Chi-Square test

Analysis of the vitamin D level intable $4 a$ in relation to gender showed a predominantly lower level for males (on average $19.6 \mathrm{ng} / \mathrm{ml}$ ) compared to females (on average $25.45 \mathrm{ng} / \mathrm{ml}$ ) being statistically significant $(p=0.02)$. Melatonin levels were slightly lower for females, but overall it was not very different compared to males, the average falling within the normal range. However, the values of the female population were more homogeneous with a standard deviation lower than that of the male. The differences were not statistically significant between the genders for melatonin values. 
TABLE 5. Comparison between the level of vitamin $D$ and the season in which the patient was analyzed

\begin{tabular}{|l|c|c|c|c|}
\hline 25-OH-vitamin D & Winter & Spring & Summer & Autumn \\
\hline Total & 5 & 15 & 52 & 29 \\
\hline Mean & 28 & 16,6 & 24,78 & 25,5 \\
\hline$S D$ & 5,12 & 5,23 & 8,72 & 9,19 \\
\hline$P^{*}$ & \multicolumn{5}{|c|}{.000134} \\
\hline
\end{tabular}

*One-way ANOVA

Comparison of the vitamin D level with the season in which the analysis was performed is shown in table 5 , where significant differences are noticed $(p=$ 0.0001 ). In our study, spring recorded the lowest average level of vitamin $D(16.6 \mathrm{ng} / \mathrm{ml}$ on average).

TABLE 6. The association between vitamin D level and melatonin, calcium, patient age, Cobb angle

\begin{tabular}{|l|c|c|c|c|}
\hline 25-OH-vitamin D & Melatonin & Calcium & Age & Cobb angle \\
\hline$r$ & 0.2357 & 0.0973 & 0.158 & -0.472 \\
\hline$P$ & 0.017654 & 0.001 & $<0.001$ & $<0.001$ \\
\hline
\end{tabular}

*Pearson correlation test

Statistical correlations between $25-\mathrm{OH}$-vitamin D level and melatonin, calcium, patient age, Cobb angle were made in table 6 . Melatonin level was positively correlated with vitamin $D$ level $(p=.017654, r=$ $0.2357)$. Vitamin $D$ level correlated positively with calcium level $(p=0.01, r=0.973)$, but also with the patient's age $(p<0.001, r=0.158)$. Cobb angle was negatively correlated with serum vitamin D level $(p<0.01$, $r=-0.472$ ).

TABLE 7. The association between melatonin level, patient age and Cobb angle

\begin{tabular}{|l|c|c|}
\hline Melatonin & Age & Cobb angle \\
\hline$r$ & 0.0715 & 0.2607 \\
\hline$P$ & .477 & .008461 \\
\hline
\end{tabular}

*Pearson correlation test

Following the results shown in table 7, calculations were made regarding the statistical association between melatonin level, age and Cobb angle. Although age is positively correlated with melatonin levels, it is not statistically significant $(r=0.0715, p=0.477)$. Cobb angle correlated positively with melatonin serum level $(r=0.2607, p=0.008461)$.

TABLE 8. Comparison between the Cobb angle and the vitamin $D$ level, taking the Cobb angle as a 30 degree mark (less than 30 degrees and greater than 30 degrees)

\begin{tabular}{|l|l|l|}
\hline 25-OH-vitamin D & $<\mathbf{3 0}^{\circ}$ Cobb & \multicolumn{1}{|c|}{$\mathbf{3 0}^{\circ}$ Cobb } \\
\hline Total & 64 & 37 \\
\hline Mean vit. D & 26.65 & 19.41 \\
\hline$S D$ & 8.81 & 9.29 \\
\hline$P^{*}$ & 0.06 & \\
\hline $95 \% \mathrm{Cl}$ & {$[24.49,28.80]$} & {$[16.41,22.40]$} \\
${ }^{*}$ T-Test
\end{tabular}

It can be seen in table 8 the division of patients taking the Cobb angle limit of $30^{\circ}$. No significant statistical correlation could be observed between vitamin $D$ level and the two groups below $30^{\circ}$ and over $30^{\circ} \mathrm{Cobb}$ angle $(p=0.06)$.

TABLE 9. Comparison between the Cobb angle and the serum melatonin level, taking the Cobb angle as 30 degrees (less than 30 degrees and greater than 30 degrees)

\begin{tabular}{|l|c|c|}
\hline Melatonin & $<\mathbf{3 0 ^ { \circ }} \mathbf{C o b b}$ & $>\mathbf{3 0 ^ { \circ }} \mathbf{C o b b}$ \\
\hline Total & 64 & 37 \\
\hline Mean melatonin & 8.44 & 9.48 \\
\hline$S D$ & 6.71 & 6.95 \\
\hline$P^{*}$ & \multicolumn{2}{|c|}{$<0.00001$} \\
\hline $95 \% \mathrm{Cl}$ & {$[24.49,28.80]$} & {$[16.41,22.40]$} \\
${ }^{*}$ T-Test
\end{tabular}

The results shown in table 9 show a positive correlation between melatonin level and the two groups below $30^{\circ}$ and over $30^{\circ}$ Cobb angle $(p<0.00001)$.

\section{DISCUSSIONS}

Discussions on the link between melatonin and the etiology of scoliosis have aroused interest among researchers in recent decades [22], starting with the studies of Machida et al., who concluded that following removal of the pineal gland chickens will develop a scoliosis similar to idiopathic scoliosis of the adolescent $[17,18,21]$. The same group studied melatonin levels in a group of 30 patients and found that $35 \%$ of them had lower levels at night compared to the control group. Bagnall KM et al. restored the study, but on a much smaller group of patients, 7 in the study group and 7 in the control group, regarding the level of melatonin during the day and at night, without finding different results. Fagan $A B$ et al. measured the level of urinary excreted melatonin for 24 hours, following a batch of 19 patients with scoliosis and 23 patients in the control group without proving a statistically significant difference [24]. Brodner et al. followed the circadian secretion of melatonin and the urinary excretion of 6-hydroxy-melatonin-sulfate in a batch of 9 patients with scoliosis who were to be operated on a batch of age-matched and gender-matched controls, but without finding statistically significant differences [25].

In our study group, 101 patients were monitored for melatonin level, and the results showed that more than half of the patients $(56-55.44 \%)$ had a low melatonin level. Melatonin level was positively correlated with $25-\mathrm{OH}$-vitamin $\mathrm{D}$ level, but had a weak positive correlation with Cobb angle when patients were divided into two groups, with Cobb angle below 30 and above 30 degrees, but statistically significant. One of the limitations of this study is the lack of comparison 
with a lot of healthy patients, of the same age and sex, regarding the level of melatonin.

Children may suffer from insufficient levels of vitamin D for various reasons. In the cold season (winter) there is less sun exposure, but also insufficient dietary intake of vitamin D $[25,26]$. Dietary intake of vitamin D, sun exposure and exercise level were not quantified in the present study. All patients were asked if they were using vitamin D, calcium or other supplements, and the answer was negative for all.

The optimal vitamin D level, measured by $25-\mathrm{OH}-\mathrm{vi}-$ tamin D, was proposed for a value of over $30 \mathrm{ng} / \mathrm{ml}$, with an ideal value between 40 and $60 \mathrm{ng} / \mathrm{ml}$. Insufficiency is considered when the level is below $20 \mathrm{ng} / \mathrm{ml}$, and between 20 and $29 \mathrm{ng} / \mathrm{ml}$ the patient is considered to have an deficiency level $[28,29]$.

A number of authors $[30,31]$ have shown that patients with idiopathic scoliosis of the adolescent have a lower level of vitamin D compared to a control group. One of the limitations of this study is the lack of comparison with an age-mached control group. However, a low level of vitamin D will have an impact on bone mineral density and the development of deformities, such as idiopathic scoliosis of the adolescent [32,33].

Calcium level was within the limits of normal for all patients. Goździalska A et al. followed in his study calcium level in a group of 200 patients, both in the control group and in the study group, where although he found significant differences between groups, the values were within the normal limits [34].

\section{CONCLUSIONS}

Patients included in this study had low levels of vitamin D, significant differences being observed between boys and girls, boys being more affected. Calcium level was within the limits of normal, with small variations. Melatonin level was below the normal limit, with more than half of the patients below the normal limit.

The positive correlation between vitamin $D$ and calcium, together with the negative correlation with Cobb angle, is yet another proof that patients with idiopathic scoliosis should be investigated regularly for these analyzes. The level of melatonin remained constant, regardless of the value of the Cobb angle, being slightly higher in patients whose Cobb angle exceeds 30 degrees.

Vitamin D and melatonin may be more important factors than have been considered so far in the onset and aggravation of idiopathic scoliosis. Larger studies, in larger populations, should be done to see if the administration of melatonin, vitamin $D$ and calcium can have an effect on the evolution of idiopathic scoliosis of the adolescent.

Conflict of interest: none declared Financial support: none declared

\section{REFERENCES}

1. Cheng JC et al. Adolescent idiopathic scoliosis. Nature reviews. Disease Primers 2015;1:15030.

2. Weinstein SL, Dolan LA, Cheng JC, Danielsson A, Morcuende JA. Adolescent idiopathic scoliosis. Lancet 2008;371:15271537.

3. Jianu M. Diagnostic precoce şi tratament in scolioza idiopatică. Pro Editura si Tipografie, 2010. ISBN 978-973-145-260-9.

4. Kikanloo SR, Tarpada SP, Cho W. Etiology of Adolescent Idiopathic Scoliosis: A Literature Review. Asian Spine J. 2019;13(3):519-526.

5. Grauers A., Rahman I., Gerdhem P. Heritability of scoliosis. Eur Spine J. 2012;21(6):1069-1074.

6. Kindsfater K, Lowe T, Lawell P, et al. Levels of platelet calmodulin for the prediction of progression and severity of adolescent AIS. J Bone Jt Surg [Am] 1994;76:1186-1192.

7. Cheng JC, Guo X, Sher AH. Persistent osteopenia in adolescent idiopathic scoliosis. A longitudinal follow up study. Spine (Phila Pa 1976) 1999; 24:1218-1222.

8. Leboeuf D, Letellier K, Alos N, Edery P, Moldovan F. Do estrogens impact adolescent idiopathic scoliosis? Trends Endocrinol Metab. 2009;20:147-152.
9. Sadat-Ali M, al-Habdan I, al-Othman A. Adolescent idiopathic scoliosis. Is low melatonin a cause? Joint Bone Spine. 2000;67(1):62-4

10. Herdea A, Stanciu A, Ulici A, Cîrstoiu C. Is melatonin involved in the etiopathology of idiopathic scoliosis? A systemic analysis of the specialty literature. Medic.ro. 2016; 114:84-87.

11. Machida M., Dubousset J., Imamura Y., et al. A possible role in pathogenesis of adolescent idiopathic scoliosis. Spine. 1996;21(10):1147-1152.

12. Cheng JC, Qin L, Cheung CS, Sher AH, Lee KM, Ng SW, Guo X. Generalized low areal and volumetric bone mineral density in adolescent idiopathic scoliosis. J Bone Miner Res. 2000;15:1587-1595.

13. Thomas KA, Cook SD, Skalley TC, Renshaw SV, Makuch RS, Gross M, et al. Lumbar spine and femoral neck bone mineral density in idiopathic scoliosis: A follow-up study. J Pediatr Orthop. 1992;12:235-240.

14. Patton CM, Powell AP, Patel AA. Vitamin D in orthopaedics. J Am Acad Orthop Surg. 2012;20:123-129.

15. Pellicane AJ, Wysocki NM, Mallinson TR, Schnitzer TJ. Prevalence of 25-hydroxyvitamin $\mathrm{D}$ deficiency in the acute inpatient rehabilitation population and its effect on function. Arch Phys Med Rehabil. 2011;92:705-711.

16. Suh KT, Lee SS, Hwang SH, Kim SJ, Lee JS. Elevated soluble receptor activator of nuclear factor-kappaB ligand and reduced bone mineral density in patients with adolescent idiopathic scoliosis. Eur Spine J. 2007;16:1563-1569.

17. Machida M, et al. Role of melatonin deficiency in the development of scoliosis in pinealectomised chickens. J Bone Joint Surg Br. 1995;77:134-8.

18. Machida M, et al. Experimental scoliosis in melatonin-deficient C57BL/6J mice without pinealectomy. J Pineal Res. 2006;41:1-7.

19. Janssen MM, et al. Experimental animal models in scoliosis research: a review of the literature. Spine J. 2011;11:347-58.

20. Cheung KM, et al. Primary thoracolumbar scoliosis in pinealectomized chickens. Spine. 2003;28:2499-504.

21. Machida M, et al. Pathologic mechanism of experimental scoliosis in pinealectomized chickens. Spine. 2001;26:E385-91.

22. Abdel-Wanis ME, Kawahara N, Tomita K. The association of neurofibromatosis 1 and 
spinal deformity with primary

hyperparathyroidism and osteomalacia:

Might melatonin have a role? J Orthop Sci. 2001;6(2):193-8.

23. Machida M, Dubousset J, Imamura Y, Miyashita Y, Yamada T, Kimura J. Melatonin. A possible role in pathogenesis of adolescent AIS. Spine. 1996;21:11471152.

24. Fagan AB, Kennaway DJ, Sutherland AD. Total 24-hour melatonin secretion in adolescent idiopathic scoliosis: A case-control study. Spine. 1998;23(1):4146.

25. Mithal A, Wahl DA, Bonjor JP, et al. Global vitamin $D$ status and determinants of hypovitaminosis D. Osteoporos Int. 2009;20:1807e20.

26. Parry J, Sullivan E, Scott AC. Vitamin D sufficiency screening in preoperative pediatric orthopedic patients. J Pediatr Orthop. 2011;31:331e3.

27. Bischoff-Ferrari HA, Giovannucci E, Willett WC, Dietrich T, Dawson-Hughes B.
Estimation of optimal serum concentrations of 25-hydroxyvitamin $\mathrm{D}$ for multiple health outcomes. Am J Clin Nutr. 2006; 84:18-28.

28. Cesareo R, Attanasio R, Caputo M, et al. Italian Association of Clinical Endocrinologists (AME) and Italian Chapter of the American Association of Clinical Endocrinologists (AACE) Position Statement: Clinical Management of Vitamin D Deficiency in Adults. Nutrients. 2018;10(5):546.

29. Suh KT, Lee SS, Hwang SH, Kim SJ, Lee JS. Elevated soluble receptor activator of nuclear factor-kappaB ligand and reduced bone mineral density in patients with adolescent idiopathic scoliosis. Eur Spine J. 2007;16:1563-1569.

30. Balioglu MB, Aydin C, Kargin D, Albayrak A, Atici Y, Tas SK, Kaygusuz MA. Vitamin-D measurement in patients with adolescent idiopathic scoliosis. J Pediatr Orthop B. 2017;26(1):48-52.

31. Xia CW, Qiu Y, Sun X, Qiu XS, Wang SF, Zhu ZZ, et al. Vitamin D receptor gene polymorphisms in female adolescent idiopathic scoliosis patients. Zhonghua Yi Xue Za Zhi. 2007;87(21):1465-9.

32. Suh KT, Eun IS, Lee JS. Polymorphism in vitamin $\mathrm{D}$ receptor is associated with bone mineral density in patients with adolescent idiopathic scoliosis. Eur Spine J. 2010;19(9):1545-50.

33. Chen WJ, Qiu Y, Zhu F, Zhu ZZ, Sun X, Liu $Z$, Chen ZJ. Vitamin D receptor gene polymorphisms: no association with low bone mineral density in adolescent idiopathic scoliosis girls. Zhonghua Wai Ke Za Zhi. 2008;46(15):1183-6.

34. Goździalska A, Jaśkiewicz J, Knapik-Czajka M, Drąg J, Gawlik M, Cieśla M, Kulis A, Zarzycki D, Lipik E. Association of Calcium and Phosphate Balance, Vitamin D, PTH, and Calcitonin in Patients With Adolescent Idiopathic Scoliosis. Spine (Phila Pa 1976). 2016;41(8):693-7. 